\title{
Contrast Preservation in Dialects of North Levantine Arabic
}

\author{
Sarah Ouwayda \\ University of Southern California \\ ouwayda@gmail.com
}

This paper uses Contrast Preservation Theory to account for two opaque processes in two dialects of Levantine Arabic spoken in Tripoli: (1) a Push Shift effect in a dialect spoken in traditional neighborhoods and (2) a constraint paradox in the standard dialect. Contrast Preservation Theory advances the idea that the preservation of contrast is an independent principle in the grammar, rather than a derivative of the interplay of other constraints as in standard Optimality Theory (OT; Prince \& Smolensky 1993). In Contrast Preservation Theory, candidate scenarios (input/output mappings) compete, rather than candidate outputs in isolation (Flemming 1995, 1996; Padgett 1997, 2003; Lubowicz 2003, 2009).

\section{I - Push Shift Effect: The Case of Old-Tripoli Dialect [a] Epenthesis}

To avoid complex codas, Lebanese Arabic places an epenthetic vowel between the last two consonants in the word. In the Old-Tripoli dialect, this vowel is [a].

\section{Examples of [a] epenthesis}

\begin{tabular}{|l|l|l|}
\hline Input & Output & Gloss \\
\hline bahr & ba.har & Sea \\
\hline Pakl & Pa.kal & Food \\
\hline lams & la.maS & Lightning \\
\hline ḍarb & da.rab & Beating \\
\hline
\end{tabular}

Thus, underlyingly CVCC words surface as CV.CaC. Words that are underlyingly $\mathrm{CVCaC}$, in turn, undergo a vowel change, such that the /a/ surface as [?].

\section{Vowel backing in contrast-neutralizing contexts}

\begin{tabular}{|l|l|l|}
\hline Input & Output & Gloss \\
\hline ba.har & ba.hor & Embarked \\
\hline Pa.kal & la.kəl & Ate \\
\hline la.maS & la.məS & Sparkled \\
\hline da.rab & da.rob & Hit \\
\hline
\end{tabular}

These data are easily accounted for using PRESERVE CONTRAST as a constraint on scenarios, where preserving contrast $(\mathrm{PC}(\mathrm{V} / 0))$ is ranked higher than maintaining the vowel quality of the input (PC(round)) and lower than the ban on complex codas.

\section{Contrast Preservation Theory explanation}

\begin{tabular}{|c|c|c|c|c|}
\hline Scenarios & Mappings & $* \mathrm{CCl \sigma}$ & $\mathrm{PC}(\mathrm{V} / 0)$ & $\begin{array}{l}\text { PC(roun } \\
\text { d) }\end{array}$ \\
\hline $\begin{array}{l}\text { Faithful } \\
\text { Scenario }\end{array}$ & $\begin{array}{l}\text { Pakl } \rightarrow \text { Pakl } \\
\text { Pakal } \rightarrow \text { ?akal }\end{array}$ & $* !$ & & \\
\hline $\begin{array}{l}\text { Contrast } \\
\text { Neutralizing }\end{array}$ & $\begin{array}{l}\text { Pakl } \rightarrow \text { ?akal } \\
\text { Pakal } \rightarrow \text { ?akal }\end{array}$ & & $* !$ & \\
\hline $\begin{array}{l}\text { Contrast } \\
\text { Preserving }\end{array}$ & $\begin{array}{l}\text { Pakl } \rightarrow \text { Pakal } \\
\text { Pakal } \rightarrow \text { ?akıl }\end{array}$ & & & $*$ \\
\hline
\end{tabular}


The process /a/ $\rightarrow$ [ग] does not take place when the word is unambiguous:

\section{Control cases}

\begin{tabular}{|l|l|l|l|}
\hline & Input & Output & Gloss \\
\hline Epenthetic & zabț & Zabat & Ticket \\
\hline Non-epenthetic backing & zabaṭ & zaboṭ & it got fixed \\
\hline Non-epenthetic no backing & zabat-lu & Zabațlu & it got fixed for him \\
\hline Non-epenthetic no backing & zabat-u-lna & Zabațulna & they got fixed for us \\
\hline
\end{tabular}

When there is a disambiguating morphological context, e.g. a verbal suffix such as $\{-1 \mathrm{u}\}$, the verb (which lacks epenthesis) is distinct from the noun (which has an epenthetic [a]), regardless of the number of suffixes.

\section{No epenthetic back vowels}

\begin{tabular}{|l|l|c|c|}
\hline Scenarios & Mappings & DEP and *back & Ident-IO [vowel] \\
\hline $\begin{array}{l}\text { Permuted } \\
\text { Scenario }\end{array}$ & Pakl $\rightarrow$ Pakol & $* !$ & \\
\hline $\begin{array}{l}\text { Winner } \\
\text { Scenario }\end{array}$ & Pakl $\rightarrow$ Pakal & & \\
\hline
\end{tabular}

Constraint conjunction is used to account for the choice of the winner scenario over the permuted scenario (Moreton \& Smolensky 2002).

\section{II - A Ranking Paradox: Standard Tripoli Dialect [e] Epenthesis}

This second set of data deals with an opaque process in the verbal domain:

$$
\begin{aligned}
& \mathrm{CaCaCC} \rightarrow \mathrm{CCaCeC} \\
& \mathrm{CaCaCeC} \rightarrow \mathrm{CaCCeC}
\end{aligned}
$$

\begin{tabular}{|c|c|c|}
\hline Input & Tripoli Output & Gloss \\
\hline $\begin{array}{l}\text { Darabt } \\
\text { Darabet }\end{array}$ & $\begin{array}{l}\text { drabet } \\
\text { ḍarbet }\end{array}$ & $\begin{array}{l}\text { I/you hit } \\
\text { She hit }\end{array}$ \\
\hline $\begin{array}{l}\text { sa?alt } \\
\text { saPalet }\end{array}$ & $\begin{array}{l}\text { s?alet } \\
\text { sa?let }\end{array}$ & $\begin{array}{l}\text { I/you asked } \\
\text { She asked }\end{array}$ \\
\hline $\begin{array}{l}\text { Šalaht } \\
\text { šalahet }\end{array}$ & $\begin{array}{l}\text { Šlaћet } \\
\text { Šalhet }\end{array}$ & $\begin{array}{l}\text { I/you undressed } \\
\text { She undressed }\end{array}$ \\
\hline $\begin{array}{l}\text { Sakabt } \\
\text { sakabet }\end{array}$ & $\begin{array}{l}\text { Skabet } \\
\text { Sakbet }\end{array}$ & $\begin{array}{l}\text { I/you poured } \\
\text { She poured }\end{array}$ \\
\hline
\end{tabular}

\section{Vowel epenthesis in complex codas}

Thus, preventing complex codas is ranked higher than avoiding epenthesis in the standard Tripoli dialect, as well $(* \mathbf{C C}] \boldsymbol{\sigma}>>$ DEP $)$.

We can conclude from the facts relating to $1^{\text {st }} / 2^{\text {nd }}$ person conjugation that foot binarity is ranked higher than preserving input vowels, as tri-syllabic words drop one vowel. Thus, in standard OT terms, FtBin $>>*[\boldsymbol{\sigma} \mathbf{C C}$. 


\section{FtBin $>>*[\sigma \mathrm{CC}$ (Dropping a vowel)}

\begin{tabular}{|c|c|c|c|}
\hline darabt (I/you hit) & FtBin & $*[\sigma$ CC & DEP \\
\hline dia.ra.bet & $* !$ & & \\
\hline dra.bet & & $*$ & $*$ \\
\hline
\end{tabular}

It is also evident from the facts of $3^{\text {rd }}$ person conjugation that foot binarity is ranked higher than the ban on complex codas.

\section{8. $\mathrm{FtBin}>>* \mathrm{CCl} \sigma$}

\begin{tabular}{|c|c|c|c|}
\hline darabet (she hit) & FtBin & $*$ CC] & DEP \\
\hline da.ra.bet & $* !$ & & \\
\hline dar.bet & & $*$ & $*$ \\
\hline
\end{tabular}

The paradox arises when trying to rank $*$ CODA with respect to $*[\sigma \mathrm{CC}$. Based on the $1^{\text {st }} / 2^{\text {nd }}$ person conjugation, we would, in standard OT, rank *CODA higher than $*[\sigma \mathrm{CC}$, as the first vowel is deleted, resulting in a complex onset in the first syllable (as shown in 9). However, the $3^{\text {rd }}$ person conjugation suggests the opposite ranking, because the second vowel in the word is deleted, resulting in a coda in the first syllable (as shown in 10).

9. *CODA $>>*$ [ $\boldsymbol{\sigma}$ CC (FtBin preserving strategy: drop the first vowel)

\begin{tabular}{|c|l|l|}
\hline darabt & *CODA & *[ $[\boldsymbol{\sigma}$ CC \\
\hline dar.bet & $* !$ & \\
\hline dira.bet & & $*$ \\
\hline
\end{tabular}

10. *[ $\boldsymbol{\sigma} \mathbf{C C}>>$ *CODA (FtBin preserving strategy: drop the second vowel)

\begin{tabular}{|c|c|c|}
\hline ḍarabet & $*[\boldsymbol{\sigma}$ CC & *CODA \\
\hline dra.bet & $* !$ & $*$ \\
\hline dar.bet & & $*$ * \\
\hline
\end{tabular}

While these data constitute a paradox in standard OT, the issue is straightforwardly resolved using Tokenized Markedness in Contrast Preservation Theory (Lubowicz 2003). For a given output $\mathrm{O}_{i}$ that violates some constraint, $\mathrm{O}_{i}$ scores one violation of Tokenized Markedness for every input (in a given scenario) that maps onto it.

\section{Tokenized markedness: Two scenarios}

\begin{tabular}{|c|c|}
\hline Coda Scenario & Complex onset Scenario \\
\hline $\begin{array}{l}1^{\text {st }} \text { pers. } \mathrm{CaCaCC} \longrightarrow \mathrm{CaCCeC} \\
2^{\text {nd }} \text { pers. } \mathrm{CaCaCC} \longrightarrow \mathrm{CCaCeC} \\
3^{\text {rd }} \text { pers. } \mathrm{CaCaCeC} \longrightarrow \mathrm{CaC}\end{array}$ & $\begin{array}{l}1^{\text {st }} \text { pers. } \mathrm{CaCaCC} \longrightarrow \mathrm{CCaCeC} \\
2^{\text {nd }} \text { pers. } \mathrm{CaCaCC} \longrightarrow \mathrm{CaCCeC} \\
3^{\text {rd }} \text { pers. } \mathrm{CaCaCeC} \longrightarrow \mathrm{CaC}\end{array}$ \\
\hline
\end{tabular}

In the coda scenario: Two inputs $\left(1^{\text {st }} / 2^{\text {nd }}\right.$ person $)$ map onto the output violating *CODA, and one $\left(3^{\text {rd }}\right.$ person $)$ maps onto the output violating $*[\sigma \mathrm{CC}$.

In the complex onset scenario: Two inputs $\left(1^{\text {st }} / 2^{\text {nd }}\right.$ person $)$ map onto the output violating $*\left[\sigma \mathrm{CC}\right.$, and one input ( $3^{\text {rd }}$ person) maps onto the output violating *CODA.

This allows us to rank the two constraints based on which of the two scenarios is chosen. 
12. Resolving the paradox: *CODA $>>*[\sigma \mathrm{CC}$

\begin{tabular}{|c|c|c|c|c|}
\hline Scer & arios & Mappings & *CODA & ${ }^{*}[\sigma \mathrm{CC}$ \\
\hline & $\begin{array}{l}\text { Coda } \\
\text { Scenario }\end{array}$ & $\begin{array}{l}\text { da.rabt } \longrightarrow \text { dar.bet } \\
\text { da.rabt } \\
\text { da.ra.bet dọ.bet }\end{array}$ & $* * !$ & $*$ \\
\hline 128 & $\begin{array}{l}\text { Complex } \\
\text { Onset } \\
\text { Scenario }\end{array}$ & $\begin{array}{l}\text { da.rabt } \longrightarrow \text { dra.bet } \\
\text { da.rabt } \\
\text { da.ra.bet } \longrightarrow \text { dar.bet }\end{array}$ & $*$ & $* *$ \\
\hline
\end{tabular}

Having resolved the ranking paradox, we can provide a Contrast Preservation Theory explanation for the winning scenario, rather than a scenario in which all inputs map onto the same output:

\section{Contrast Preservation Theory explanation}

\begin{tabular}{|c|c|c|c|c|c|}
\hline \multicolumn{2}{|c|}{ Scenarios } & Mappings & PC & ${ }^{*} \operatorname{CODA}$ & ${ }^{*}[\sigma \mathrm{CC}$ \\
\hline & $\begin{array}{l}\text { Contrast } \\
\text { neutralizing }\end{array}$ & $\begin{array}{l}\text { da.rabt }>\text { ḍa.bet } \\
\text { ḍa.rabt } \\
\text { ḍa.ra.bet }\end{array}$ & $* !$ & & $* * *$ \\
\hline 158 & $\begin{array}{l}\text { Contrast } \\
\text { preserving }\end{array}$ & $\begin{array}{l}\text { da.rabt } \longrightarrow \text { ḍa.bet } \\
\text { ḍa.rabt } \\
\text { ḍa.ra.bet } \longrightarrow \text { dar.bet }\end{array}$ & & $*$ & $* *$ \\
\hline
\end{tabular}

Contrast Preservation Theory thus provides a straightforward account to both sets of data. In the Old Tripoli dialect, it resolves the issue of why the same morpheme behaves differently depending on whether it is ambiguous or has a disambiguating phonological context, and in the standard Tripoli dialect, it resolves a ranking paradox.

\section{Selected References:}

Flemming, Edward. 1995. Auditory Representations in Phonology. Ph.D. dissertation, UCLA.

Ito and Mester 2004. Morphological contrast and merger: ranuki in Japanese. Journal of Japanese Linguistics 20.

Lubowicz 2003. Contrast Preservation in Phonological mappings. PhD dissertation. University of Massachussets Amherst.

Padgett, 1997. Perceptual distance of contrast: vowel height and nasality. In Rachel Walker, Motoko Katayama, and Daniel Karvonen, eds., Phonology at Santa Cruz 5, Linguistics Research Center, UC Santa Cruz.

Prince and Smolensky. 1993. Optimality Theory: Constraint Interaction in Generative Grammar, Rutgers University, New Brunswick, NJ. Report RUCCS TR-2. 